\title{
Learning Design for Creating a Lifelong Learning Organization
}

\author{
Ulla Widmark and Eeva Koroma \\ Stockholm University, Teacher Education, Sweden
}

\begin{abstract}
Our learning design for lifelong learning has been developed during the past ten years at the Teacher Education unit at Stockholm University. The same design but with different content has been used to higher the competence of different target groups; teachers in the field, policemen, medical personal, headmasters etc. As an example we will present our learning design for the course "Steps for Skills" which was a government appointed, multi-year national initiative to support municipalities' long-term quality and skills development in health and social care for older people. The purpose of the Steps for Skills was to improve the internal quality of health and social care. This was to be achieved by developing the skills of the staff working close to older people.
\end{abstract}

Keywords: Learning design, lifelong learning, blended learning, collaborative learning, Communication, Learning Dialogue.

\section{Courses at Stockholm University}

During the year 2006 two courses for the "Steps of skills" initiative were implemented at the Teacher Education unit in collaboration with Ministry of Health and Social Affairs national investment on skill development within the geriatric care. The participants were recruited from those six municipalities that participated in Steps of Skills pilot course. Tutor education during the spring of 2006 had 23 participants. The course during the autumn had 43 participants.

There were four different staff categories within geriatric care that were involved in our course:

- $\quad$ tutors, a new role with educational responsibilities (mostly assistant nurses)

- operating chiefs with responsibilities for the organizations and local units

- $\quad$ elected union representatives with focus on the staff's working situation and the skill development of the staff

- teachers - with the assignment to develop the geriatric care's pedagogy and with responsibilities for learning and validating.

The courses' common aims were to give the participants:

- deepened knowledge about a workplace as a learning organization

- knowledge about the educational content in College Coaching and the Learning Dialogue 
- $\quad$ resources to develop the geriatric care's organization and individuals and groups in it

- $\quad$ to become familiar with net based learning environment.

The content in the courses connect with the experiences the participants have from their work within the geriatric care and from current research and literature. The content was also concerned about the staff's needs for competence and skill development. It concerned the production teams' need of education and the participants' individual needs. It included also analysis of intentions, visions and action plans but the participants would also learn about the importance of digital technology for learning and work. We linked the practical experiences of Learning Dialogue to pedagogical literature about leadership, colleague tutoring and activity development. A very important element in the education was to implement a project activity on your own working unit with your stuff members. By doing a project the participants got experiences of how to build up and develop learning activities at work.

The courses were carried out both through physical and digital meetings. Between the campus seminars the participants met on web seminars. Thus the courses were built on two different learning environments; one physical and one digital. During the physical meetings, the educational methods were the same as during the digital meetings.

A detailed study plan for the entire course was prepared. It shows with clarity how the course is built-up and what educational methods are to foster the skill development. The aim was that the participants not only would have theoretical and methodical knowledge. They would also need to be able to use the new educational role that they were to become familiar with. The course included elements of educational ICT i.e. knowledge about how electronic tools can be used for the learning activity.

During the course's time and after the completed course, the work was evaluated with an electronic tool in aim to develop and to improve the shapes and the methods for the skill development.

The participants have continuously been examined. After each web seminar both common and individual contributions documented on our virtual platform were presented. We wanted thereby to emphasize the importance of learning processes, not only the end product. During the ultimate campus seminar the participants presented both orally and in written reports what they had learned. They presented various proposals for improvements in skill development. Our experience told us, as does the collaborative theory about learning, that the link between physical and social activities and the digital presence has had importance for interaction.

The educational tools on our virtual platform were exchanges of experience, literature analyses, written contributions, responses and discussions. The communication on the platform was flexible i.e. independent of time and place. The communication moved forward through participants' own questioning where argumentation and responses were included. The documents on the web were preserved and developed over the time. During the course's time, the participants had mutual access to each others' communication, documentation and learning. The platform enables text, picture, sound and multimedia presentations to be published. 
An important learning resource during the studies was the participants' own practice experience. It meant that the participants actively worked with analyzing their practice experience and other participants' experiences in the light of educational/didactic theory. We organized study groups heterogeneously so that different experiences were represented in the groups. The participants in the study groups shared the responsibility for learning and interaction. The task to lead and to summarize a group's work rotated among the members.

The meaning of the course was that the studies were to be anchored in the occupational role i.e. the professional thinking and acting. Educational research of learning that focuses on practice communities has quickly won territory. Jean Lave and Etienne Wenger presented a model for the situated learning where they emphasize that learning can be linked to participation in what they call practice communities which can to be both institutional and spontaneous.

From a course evaluation we can read following participant's comment concerning the task to summarize a discussion:

"In my group we have been precise with the fact that we should all the time return to the issue we had chosen to discuss although we have given ourselves time to" fly out". To summarize and to speculate on if the issue is responded to or not, to write comments on the discussion is very important to learn in order to see the whole picture, to learn to have a global approach."

According to theory about Computer Supported Collaborative Learning the participant is considered as an individual with potentials, perfectible capabilities and knowledge. An education on the basis of this perspective of learning and learners requires a practical exercise, activities of various kinds. Knowledge builds on the relation between the thought and the activity, between to learn and to do, between theory and practice.

\section{The Learning Dialogue Method}

The educational method, the Learning Dialogue, is one now well-known method for tutoring and coaching. The aim of the method is to, in a structural way, formulate questions around a professional activity, to lift up the resemblances and differences for discussion, thus not primarily in order to find solutions or just to complete the tasks. The answers and the solutions are more associated with the implementation of practical experiments. The Learning Dialogue is characterized as a dialogical approach on learning than one of defending a thesis. The dialogue is carried out in a group where everyone takes part in the conversation and all the ideas and thoughts become visible i.e. they all contribute to mutual learning and everyone involved shares the responsibility to ensure the dialogue.

The dialogue is to alternate between different levels on learning; activities, experiences, values and theories. The aim is that the group is enhanced a common attitude to its professional role. From a perspective more characterized of authenticity, anchored in reality, the learners' practical experiences and even the attitude to change, development and hopefully improvement develops. 
An educational method for learning requires tools. The tools for the Learning Dialogue are: listening, asking, structuring in levels and different perspectives of organizations. Reflection is of great importance as is the documentation of the participants' reflections. Participation in the dialogue is central. Everyone in the group is to present their thoughts.

\section{The Participants' Reflections on Education}

We choose here to show some glimpses of the course for tutors where the participants in their final report present their view on "The Steps of Skills" education. The quotations are selected on the basis of the description we did around the method of learning dialogue that the participants learned to apply in their working practise where their task have been to develop the skills of the geriatric care's personnel.

"This course has meant hugely for me, I have developed as a person. Through all these meetings with different people, through knowledge that I have achieved, through literature and above all through the Learning Dialogue. All this has got me to see people, situations and events with new eyes and from other perspectives. My focus, awareness has increased, my self-confidence has grown and I have become a safer person. I have now a greater desire to learn and to acquire knowledge."

This quotation is representative for how the participants describe their personal and professional development. The course has built up their self-confidence in the new role as a tutor and the perspectives on working practice has been stimulating and motivating. The participants have both recognized and developed their own base of experience. They have felt that they have been part of an important phase of development in the geriatric care and their own working role has been reflected in other persons' experiences.

Learning Dialogue with its experience and practice based content, where everyone shares their learning with each other and thereby are participating in a developing process, has created strong motivation. It has simply been exciting to attend a course. Particularly exciting has been the keeping of the log where the week's work becomes an object for reflection. The digital study room and its openness in what has been documented means that the course becomes a meeting place for learning and developing of the tutor role.

The digital rooms are not the course's only meeting places. Many of the participants also describe physical meetings with managers, with colleagues and with teachers i.e. persons that have importance for how their work will be planned, to be implemented and to be evaluated, as very important. One of the participants writes this way about her future role in a big system of roles:

“As a tutor, my role is to complement teacher's work through, among other things, Learning Dialogues, support students in different situations in their practical activities and make space for reflection in and around the experience. I will also try to attract my fellow-workers to this investment and to get them to share of their knowledge, thoughts and ideas. There is an extremely big silent knowledge that should be 
lifted forward and to be used in the work. It is a part of my work to stay up and to question which actions I should take. How will I act in order to function as a good tutor?"

The link between education and activity on work contributes to the fact that the course is experienced as worthwhile, stimulating and meaningful. Someone writes that she became aware about her own attitude and thereby now can better influence her own understanding and her actions.

The participants have detected how the road to understanding goes through practical actions. Therefore, the course task, to implement the Learning Dialogue method in a working team on their own unit is an important aspect in acquiring knowledge about the role of the tutor.

\section{Analysis of Collaborative Learning}

Learning Dialogue and College Coaching are educational methods that permeate our campus meetings, the distance learning and the practical part of the education. The findings we here present and that also illustrate the education's results are seen from the participants' perspectives. The flexibility in time and place, that the distance learning makes possible, is one of many factors that influenced the result. Participation is not scheduled or connected to a certain room, adaptable conditions make it possible for the participants to choose when they want to carry out their studies. The flexibility is characterized also in the fact that the communication in this education is horizontal. The course's structure is adapted to the participants' professional situation and their individual needs and it is characterized in equal relationships between participants where hopefully each and everyone become visible.

During the education different organizations/working units with different needs and conditions meet and that makes it possible for dissemination of alternative forms of education within the care of the elderly as regards contents and arrangement. This flexible structure on the education has in a clear way contributed to the fact that different forms of skill development were disseminated and were compared with each other.

The documentation is one of the corner pillars in the course. It has clearly been exciting to follow the process shaped in the fellow participants' writing. Unlike the printed word in the literature, writing in the course been written over the time and been accumulated gradually.

We designed courses in order to carry out the learning activities on three levels:

- $\quad$ an individual level

- an interactive level and

- a practical activity level.

\subsection{The Individual Activity}

During three seminar periods students have been activate in various way. They have been diligent participants as they did what they been expected to: written work logs during the entire course, did literature tasks, responded to questions, participated in 
discussions, gave response on each others' contributions etc. This level reminds one of the traditional individual learning that permeate all education from basic level to academic level. Our assessment is that at distance learning it is important to have a clear and surely well thought-out methodical approach. This is essentially a crucial level so that the participants in the course get started, becomes participating and do their tasks. A person's absence is easily detected by an empty file.

\subsection{The Interactive Level, Learning Networks}

The interactive level has created motivation, been exciting and instructive. The participants have pursued a row of deepening discussions on the course themes, the tutor role and the Learning Dialogue. That has given new knowledge and new experiences.

Notable is that several discussions are on simultaneously and that the participants go back in order to see what has happened over the time in this interactive group learning. Compared with traditional education with seminars and literature studies this becomes an entirely new educational environment. The participants take part in each others' education for an extended period of time not only during a limited time available as in a campus course.

\subsection{The Practical Activity Level}

During the course the participants have had the task to plan, to implement and to reflect over a project based on their professional work. They have with curiosity and encouragement in a constructive way followed each others' project works. They have not only had an opportunity to take part in a final presentation but they have even been able to follow an entire process and moreover support each other in this process. The "reality near" content has given the studies its legitimacy, credibility and usefulness. There has been a feeling of recognition but at the same time a questioning of this recognition.

\section{Support for Learning}

The three levels for learning have markedly contributed to an analysis of the geriatric care's activity and to development and renewal. The digital technology in itself has made it possible for learning meetings between participants and the use of the asynchronous communication has strengthened the mutual learning.

\section{References}

1. Bjessmo, L.-E., Ulla, K.: Handledarutbildning inom äldreomsorgen (2002)

2. Bjessmo, L.-E., Ulla, K.: Att bygga kunskaper. Häften för didaktiska studier nr 75. HLS förlag

3. Bjessmo, L.-E., Karlsson, U.: Vägen till lärande går med nödvändighet genom handling. FoU-rapport. LHS 
4. Bjessmo, L.-E., Ulla, K.: Länkar i lärandets kedja. Om nätbaserat och interaktivt lärande. Liber (2008)

5. Black, P., Harrison, C., Lee, C., Marshall, B., Wiliam, y.: Assesment for learning; Putting into practice. Open University Press (2003)

6. Olga, D.: Dialog samspel och lärande. Studentlitteratur (2007)

7. Ellström, P.-E., Hultman, G.: Lärande och förändring i organisationer: om pedagogik i arbetslivet. Studentlitteratur, Lund (2006) 